\title{
Vitamin D receptor gene polymorphism: association with Crohn's disease susceptibility
}

\author{
J D Simmons, C Mullighan, K I Welsh, D P Jewell
}

\begin{abstract}
Background-The vitamin D receptor (VDR) gene represents a strong positional candidate susceptibility gene for inflammatory bowel disease (IBD). The VDR gene maps to a region on chromosome 12 that has been shown to be linked to IBD by genome screening techniques. It is the cellular receptor for $1,25(\mathrm{OH})_{2}$ vitamin $\mathrm{D}_{3}$ (calcitriol) which has a wide range of different regulatory effects on the immune system. IBD is characterised by activation of the mucosal immune system.
\end{abstract}

Aim-To determine if polymorphisms in the VDR gene are associated with susceptibility to IBD

Subjects-European Caucasoids: 158 patients with ulcerative colitis, 245 with Crohn's disease, and 164 cadaveric renal allograft donor controls.

Method-Single nucleotide polymorphisms (TaqI, ApaI, and FokI) in VDR were typed in patients with Crohn's disease, ulcerative colitis, and controls by polymerase chain reaction with sequence specific primers.

Results-There were significantly more homozygotes for the TaqI polymorphism at codon 352 of exon 8 (genotype " $t t$ ") among patients with Crohn's disease (frequency 0.22 ) than patients with ulcerative colitis $(0.12)$ or controls $(0.12)$ (odds ratio 1.99; $95 \%$ confidence interval 1.14-3.47; $\mathbf{p}=\mathbf{0 . 0 1 7 )}$.

Conclusion-This study provides preliminary evidence for a genetic association between Crohn's disease susceptibility and a gene that lies within one of the candidate regions determined by linkage analysis.

(Gut 2000;47:211-214)

Keywords: inflammatory bowel disease; genetics; candidate genes; vitamin D

There is now good familial and molecular genetic evidence that susceptibility to inflammatory bowel disease (IBD) has a strong genetic component. Genome screening by studying microsatellite marker allele sharing in affected relative pairs has demonstrated linkage to chromosomes 3, 7, 12, and $16 .{ }^{1}$ Linkage to the region on chromosome 12 has been replicated in a number of different centres in different populations. ${ }^{23}$ A strong positional candidate susceptibility gene, the vitamin D receptor (VDR) (GDB:120487, GenBank J03258) $)^{4}$ maps to this region and is closely linked to microsatellite markers at the peak of these linkage curves (within $3 \mathrm{cM}$ of D12S85; see http://www.ncbi.nlm.nih.gov/genemap).

VDR is a member of the steroid receptor family and mediates the effects of the active metabolite $1,25(\mathrm{OH})_{2}$ vitamin $\mathrm{D}_{3}$ by regulating transcription of a number of different cellular genes. ${ }^{5}$ In addition to its well known effects on calcium homeostasis, $1,25(\mathrm{OH})_{2}$ vitamin $\mathrm{D}_{3}$ has many actions on the immune system. VDR is expressed by monocytes and activated $\mathrm{B}$ and T lymphocytes, ${ }^{6}$ and $1,25(\mathrm{OH})_{2}$ vitamin $\mathrm{D}_{3}$ is synthesised by activated macrophages ${ }^{7}$ thus acting in a local paracrine manner similar to other cytokines. It activates monocytes and macrophages ${ }^{8}$ but suppresses lymphocyte proliferation and immunoglobulin production. ${ }^{9}$ It inhibits the action of the proinflammatory transcription factor $\mathrm{NF} \kappa \mathrm{B}$ and the production of a variety of different cytokines, including interleukin (IL)-2, IL-12, and interferon $\gamma \cdot{ }^{10}$

The linked, commonly occurring, single nucleotide polymorphisms at the $3^{\prime}$ end of VDR (BsmI, ApaI, and TaqI $)^{11}$ and the exon 2 splice site FokI polymorphism ${ }^{12}$ have been associated with bone mineral density and osteoporosis in a number of different populations. However, these associations have not been universally replicated and the role of VDR polymorphisms in osteoporosis has been reviewed recently. ${ }^{13}$ The TaqI polymorphism has also been associated with the risk of prostate cancer. ${ }^{14}$ More recently homozygotes for the TaqI $t$ allele have been shown to have altered susceptibility to a variety of infectious diseases. ${ }^{15}$

The pathogenesis of IBD is unknown but may relate to aberrant regulation of the mucosal immune response. We postulated that any mutation that might alter the level of expression or function of VDR might influence the likelihood of developing IBD. A case control association study was carried out to determine if the ApaI, TaqI, and FokI single nucleotide polymorphisms are associated with IBD susceptibility.

\section{Methods}

PATIENTS AND CONTROLS

European Caucasian patients with ulcerative colitis or Crohn's disease were recruited retrospectively from the IBD clinics in Oxford and High Wycombe, UK. The case notes of all patients were reviewed and a diagnosis of IBD confirmed by standard endoscopic, histopathological, and radiological criteria. A total of 158

Abbreviations used in this paper: VDR, vitamin $\mathrm{D}$ receptor; IBD, inflammatory bowel disease; PCR-SSP, polymerase chain reaction with sequence specific primers; RCLB, red cell lysis buffer; IL, interleukin. 
patients with ulcerative colitis (median age at diagnosis 38 years (range $11-87$ ); 52\% female; $66 \%$ distal ulcerative colitis; $34 \%$ extensive ulcerative colitis; $12 \%$ had undergone colectomy) were typed for the TaqI, ApaI, and FokI polymorphisms: 245 patients with Crohn's disease (median age at diagnosis 26 years (range $10-77$ ); $62.5 \%$ female; $47 \%$ ileal disease; $33 \%$ ileocolonic; $20 \%$ colonic) were typed for the TaqI polymorphism. Of these, 174 ( $71 \%$ of total) were also typed for the Apa 1 polymorphism and $165(67 \%)$ for the FokI polymorphism. Caucasoid cadaveric renal allograft donors were used as controls; 164 were typed for the TaqI polymorphism and 101 (62\%) were typed for the $A p a \mathrm{I}$ and FokI polymorphisms (median age 32 years (range 12-68); $32 \%$ female). All patients were not typed at each locus because of limited DNA availability due to the age of some of the samples. The TaqI polymorphism was given priority because of the previously reported associations between this polymorphism and susceptibility to infections disease.

\section{DNA EXTRACTION}

Genomic DNA was extracted from EDTA or trisodium citrate anticoagulated peripheral blood by a salting out method. ${ }^{16}$ The buffy coat from $5 \mathrm{ml}$ of anticoagulated blood was lysed in a red cell lysis buffer (RCLB) consisting of $0.144 \mathrm{M} \mathrm{NH}_{4} \mathrm{Cl}$ and $1 \mathrm{mM} \mathrm{NaHCO}$. After centrifugation the pellet was rinsed in RCLB and resuspended in $3 \mathrm{ml}$ of nuclear lysis buffer (0.4 M NaCl, $2 \mathrm{mM} \mathrm{Na}$ EDTA, $10 \mathrm{mM}$ Tris $\mathrm{HCl}$ ) and $200 \mu \mathrm{l}$ of $10 \%$ (w/v SDS) in water. After vigorous mixing $1 \mathrm{ml}$ of $6 \mathrm{M} \mathrm{NaCl}$ and $3 \mathrm{ml}$ of chloroform were added, vortexed, and centrifuged at $3000 \mathrm{rpm}$ for 30 minutes. DNA aspirated from the top aqueous phase was precipitated with $95 \%$ ethanol, washed in $70 \%$ ethanol, and resuspended in distilled water.

PRIMER DESIGN

Each reaction contained an allele specific primer, the 3 ' nucleotide of which determined allele specificity, and a consensus primer designed from published VDR sequences (GDB: 120487, GenBank accession J03258), and an unpublished sequence (Dr N Morrison), together with a pair of amplification control primers giving rise to a 796 base pair fragment of the third intron of HLADR B1.

TaqI " $T$ " allele 5'-CGGTCCTGGATGGC CTCA-3'

TaqI " $t$ " allele 5'-CGGTCCTGGATGGC CTCG-3'

TaqI consensus 5'-CAGAGCATGGACAGG GAGC-3'

FokI " $F$ " allele 5'-TGGCCGCCATTGCC TCCG-3'

FokI "f" allele 5'-TGGCCGCCATTGCC TCCA-3'

FokI consensus 5'-AGCTGGCCCTGGCA CTGA-3'

HLA DRB F 5'-TGCCAAGTGGAGCAC CCAA-3'

HLA DRB1 R 5'-GCATCTTGCTCTGTGC AGAT-3'
In a subset of patients and controls, the polymerase chain reactions (PCR) for the linked TaqI and ApaI polymorphisms were combined using a sequence specific primer for the ApaI polymorphism as the forward primer and a sequence specific primer (SSR) for TaqI as the reverse primer.

$A p a \mathrm{I}$ " $A$ " allele 5'-GTGGGATTGAGCAGT GAGGT-3'

ApaI " $a$ " allele 5'-GTGGGATTGAGCAGTG AGGG-3'

Four such reactions representing each of the possible combinations of $T a q \mathrm{I}$ and $A p a \mathrm{I}$ genotype ( $A-T, A-t, a-T, a-t)$ were performed to allow the chromosomal haplotypes to be identified. ${ }^{17}$

\section{AMPLIFICATION CONDITIONS}

Reaction mixtures of $13 \mu \mathrm{l}$ were used, consisting of $67 \mathrm{mM}$ Tris base $\mathrm{pH} 8.8,16.6 \mathrm{mM}$ ammonium sulphate, $2 \mathrm{mM}$ magnesium chloride, $0.01 \%(\mathrm{v} / \mathrm{v})$ Tween $20,200 \mathrm{mM}$ each of dATP, dTTP, dGTP, and dCTP, forward and reverse primers at $6.8 \mu \mathrm{M}$ each, control primers at $0.68 \mu \mathrm{M}$, between 0.1 and $0.01 \mu \mathrm{g}$ of DNA, and 0.1875 units of Taq polymerase (Advanced Biotechnology, London, UK). Reaction mixtures were dispensed under $10 \mu \mathrm{l}$ of mineral oil (Sigma, UK) in 96 well PCR plates (Costar, High Wycombe, UK).

DNA samples were amplified in GeneAmp PCR system 9600 (Perkin-Elmer Corporation) or in MJ Research PTC-200 thermal cyclers with cycling parameters as follows: one minute at $96^{\circ} \mathrm{C}$ followed by five cycles of $96^{\circ} \mathrm{C}$ for 25 seconds, $70^{\circ} \mathrm{C}$ for 45 seconds, and $72^{\circ} \mathrm{C}$ for 45 seconds, followed by 21 cycles of $96^{\circ} \mathrm{C}$ for 25 seconds, $65^{\circ} \mathrm{C}$ for 50 seconds, and $72^{\circ} \mathrm{C}$ for 45 seconds, followed by four cycles of $96^{\circ} \mathrm{C}$ for 25 seconds, $55^{\circ} \mathrm{C}$ for 60 seconds, and $72^{\circ} \mathrm{C}$ for 120 seconds. PCR plates were sealed with Thermowell sealers (Costar) and dipped in mineral oil to improve plate to block contact.

GEL ELECTROPHORESIS AND PRODUCT DETECTION Following PCR, $5 \mu \mathrm{l}$ of loading buffer consisting of $0.25 \%$ Orange G, $30 \%$ v/v glycerol, and $0.5 \times$ TBE buffer $(89 \mathrm{mM}$ Tris base, $89 \mathrm{mM}$ boric acid, 2 mM EDTA, $\mathrm{pH}$ 8.0) were added to each reaction mix. PCR products (amplicons) were then electrophoresed in $1.0 \%$ agarose gels containing $0.5 \mu \mathrm{g} / \mathrm{ml}$ ethidium bromide for $20-25$ minutes at $15 \mathrm{~V} / \mathrm{cm}$ in $0.5 \times$ TBE buffer, visualised with UV illumination, and photographed with a Polaroid land camera.

\section{STATISTICAL ANALYSIS}

Genotype, individual allele frequencies, and phenotype frequencies (proportion possessing one or more copies of an allele) were calculated. The genotyping results were initially analysed with the $\chi^{2}$ test using a $3 \times 3$ contingency table and if this indicated a significant association $(\mathrm{p}<0.05)$ then each individual genotype was analysed using a $2 \times 2$ contingency table with Fisher's exact test, and the odds ratio calculated. 
Table 1 Vitamin D receptor genotype frequencies

\begin{tabular}{|c|c|c|c|c|c|c|}
\hline \multirow[b]{2}{*}{ Genotype } & \multicolumn{2}{|c|}{ Crohn's disease } & \multicolumn{2}{|c|}{$\begin{array}{l}\text { Ulcerative } \\
\text { colitis }\end{array}$} & \multicolumn{2}{|c|}{ Control } \\
\hline & $n$ & $f$ & $\bar{n}$ & $f$ & $\bar{n}$ & $f$ \\
\hline$\overline{A T / A T}$ & 3 & 0.02 & 8 & 0.05 & 1 & $0.01^{\mathrm{ab}}$ \\
\hline$A T / a T$ & 19 & 0.11 & 20 & 0.13 & 15 & 0.15 \\
\hline$A T / A t$ & 12 & 0.07 & 16 & 0.10 & 13 & 0.13 \\
\hline$a T / a T$ & 38 & 0.22 & 30 & 0.19 & 29 & 0.29 \\
\hline$a T / A t$ & 60 & 0.34 & 65 & 0.41 & 32 & 0.32 \\
\hline$A t / A t$ & 42 & 0.24 & 19 & 0.12 & 11 & 0.11 \\
\hline$A / A$ & 57 & 0.33 & 43 & 0.27 & 25 & $0.25 \mathrm{NS}$ \\
\hline$A / a$ & 79 & 0.45 & 85 & 0.54 & 47 & 0.47 \\
\hline$a / a$ & 38 & 0.22 & 30 & 0.19 & 29 & 0.29 \\
\hline$T / T$ & 84 & 0.34 & 58 & 0.37 & 64 & $0.39^{\text {cde }}$ \\
\hline$T / t$ & 108 & 0.44 & 81 & 0.51 & 80 & 0.49 \\
\hline$t / t$ & 53 & $0.22^{\mathrm{f}}$ & 19 & 0.12 & 20 & 0.12 \\
\hline$F / F$ & 61 & 0.37 & 64 & 0.41 & 30 & $0.30 \mathrm{NS}$ \\
\hline$F / f$ & 75 & 0.45 & 71 & 0.45 & 58 & 0.57 \\
\hline$f / f$ & 29 & 0.18 & 23 & 0.15 & 13 & 0.13 \\
\hline
\end{tabular}

${ }^{\mathrm{a}} \mathrm{Crohn}$ 's disease $v$ ulcerative colitis $v$ control, $\mathrm{p}=0.01$; ${ }^{\mathrm{b}} \mathrm{Crohn}$ 's disease $v$ control, $\mathrm{p}=0.01$ for trend; ${ }^{\mathrm{c}} \mathrm{Crohn}$ 's disease $v$ ulcerative colitis $v$ control, $\mathrm{p}=0.056 ;{ }^{\mathrm{d}}$ Crohn's disease $v$ control, $\mathrm{p}=0.05$ ${ }^{\mathrm{e}} \mathrm{Crohn}$ 's disease $v$ ulcerative colitis, $\mathrm{p}=0.046$; ${ }^{\mathrm{f}} \mathrm{Crohn}$ 's disease $v$ control, $t t \vee T T$ and $T t, \mathrm{p}=0.017$ (odds ratio $1.99,95 \%$ confidence interval 1.14-3.47).

\section{Results}

Overall, the TaqI genotype was significantly associated with Crohn's disease $\left(3 \times 2 \chi^{2}\right.$ test $)$ and TaqI " $t$ " allele frequency was increased in patients with Crohn's disease. Homozygosity for the TaqI " $t$ " allele (genotype " $t t$ ") was significantly more common in patients with Crohn's disease than in controls (53/245v $20 / 164$, respectively; odds ratio $1.99,95 \%$ confidence interval 1.14-3.47; Fisher's exact $\mathrm{p}=0.017$ ) (tables 1,2 ). There was no such association with ulcerative colitis. There was a non-significant association between the $A p a \mathrm{I}$ " $A A$ " genotype and Crohn's disease but this can be explained by the stronger TaqI " $t t^{\text {" }}$ association. ApaI and TaqI are separated by only 76 base pairs and the $A p a \mathrm{I}$ allele " $A$ " and TaqI allele " $t$ " were shown to be in very strong linkage disequilibrium both in patients and controls $\left(\chi^{2}=90.5\right.$ and 47.6 , respectively; $\mathrm{p}<0.001$ for both). Genotype frequencies for the FokI polymorphism were similar in patients and controls. Despite the differences in the proportion of males and females in the three groups, there was no association between genotype and sex $\left(\chi^{2}=1.05 ; \mathrm{p}=0.59\right)$. The proportions of the different TaqI genotypes in the groups typed and not typed for the other two polymorphisms were not significantly different,

Table 2 Vitamin $D$ receptor allele and phenotype frequencies

\begin{tabular}{|c|c|c|c|c|c|c|}
\hline & \multicolumn{2}{|c|}{ Crohn's disease } & \multicolumn{2}{|c|}{ Ulcerative colitis } & \multicolumn{2}{|c|}{ Control } \\
\hline & $n$ & $f$ & $n$ & $f$ & $n$ & $f$ \\
\hline \multicolumn{7}{|c|}{ Allele } \\
\hline$A$ & 193 & 0.55 & 171 & 0.54 & 97 & 0.48 \\
\hline$a$ & 155 & 0.45 & 145 & 0.46 & 105 & 0.52 \\
\hline$T$ & 276 & 0.56 & 197 & 0.62 & 208 & 0.63 \\
\hline$t$ & 214 & 0.44 & 119 & 0.38 & 120 & 0.37 \\
\hline \multicolumn{7}{|c|}{ Phenotype } \\
\hline$A$ & 136 & $0.78^{\star} \mathrm{NS}$ & 128 & $0.81^{\star} \mathrm{NS}$ & 72 & 0.71 \\
\hline$a$ & 117 & $0.67^{\star} \mathrm{NS}$ & 115 & $0.73^{\star} \mathrm{NS}$ & 76 & 0.75 \\
\hline$T$ & 192 & $0.78^{\star} \mathrm{NS}$ & 139 & $0.88^{\star} \mathrm{NS}$ & 144 & 0.88 \\
\hline$t$ & 161 & $0.66^{\star} \mathrm{NS}$ & 100 & $0.63^{\star} \mathrm{NS}$ & 100 & 0.61 \\
\hline
\end{tabular}

* Phenotype frequencies: individuals possessing one or more copies of the respective allele are compared against the number of individuals with no copy of that allele (that is, $A v$ non- $A$ ). confirming that the subgroup of Crohn's patients typed for ApaI and FokI were representative of the group as a whole (data not shown).

\section{Discussion}

This study provides preliminary evidence for a genetic association between Crohn's disease susceptibility and a gene that lies within one of the candidate regions determined by linkage analysis. While the " $t t$ " genotype was found to be associated with Crohn's disease, no association was found with ulcerative colitis. This may reflect a type 1 error in that the numbers typed were too small. However, it is consistent with linkage data suggesting that linkage to the locus on the chromosome is stronger for Crohn's disease than ulcerative colitis and that the peak linkage for Crohn's disease and ulcerative colitis may be at different markers. ${ }^{4}$ This may suggest the existence of more than one susceptibility locus in the region.

The mechanism by which the TaqI " $t t^{\text {" }}$ genotype might influence susceptibility to Crohn's disease is not clear. The TaqI polymorphism is an A to C base substitution at codon 352 of exon 8 of VDR but this does not produce an amino acid coding change (both isoleucine). It has been shown using a VDRluciferase reporter gene construct that the " $t$ " allele may be associated with increased levels of mRNA production in vitro. ${ }^{11}$ However, other investigators using a quantitative reverse transcriptase PCR method have found no allele specific differences in VDR mRNA ${ }^{18}$ or even an association between the " $t$ " allele and reduced levels of VDR mRNA. ${ }^{19}$ Evidence relating to the true functional significance of the " $t t$ " genotype is scarce and contradictory, and it is possible that the " $t$ " allele might serve as a marker for a linked but as yet unidentified functional polymorphism elsewhere in the VDR gene, or indeed in another nearby gene. No association was identified with the FokI polymorphism located at the 5' end of the VDR gene, 33.9 kilobases distant to the TaqI polymorphism, suggesting that any other putative susceptibility locus may be located further in the 3' direction from the TaqI polymorphism.

The immunoregulatory effects of $1,25(\mathrm{OH})_{2}$ vitamin $\mathrm{D}_{3}$ are complicated and the precise way in which it interacts with other regulators of the immune response is not yet clear. If the " $t t$ " genotype is associated with enhanced VDR transcription, then a stronger cell mediated immune response or increased monocyte activation might predispose to the development of Crohn's disease. An alternative explanation for these results may be the inhibitory effect of $1,25(\mathrm{OH})_{2}$ vitamin $\mathrm{D}_{3}$ on the production of IL-12, ${ }^{10}$ a cytokine central to the immune activation seen in Crohn's lesions. ${ }^{20}$ If the " $t t$ " genotype is associated with a decrease in VDR mRNA as some have suggested, then less efficient inhibition of IL-12 secretion may give rise to an enhanced Th1 immune response and thus increase susceptibility to Crohn's disease. A further mechanism may involve the mucosal humoral immune system. $1,25(\mathrm{OH})_{2}$ Vitamin $\mathrm{D}_{3}$ inhibits antibody secretion, and therefore if 
TaqI $t$ increases VDR expression, there will be enhanced vitamin D action, suppression of gut humoral immunity, and thus increased susceptibility to pathogens which may trigger or potentiate inflammation in Crohn's disease.

Of great interest are recent studies in African and Indian populations which have demonstrated associations between the " $t t$ " genotype and infectious disease, providing further biological evidence for the importance of this polymorphism in immune regulation. " $t t$ " has been shown to be associated with resistance to tuberculosis, chronic hepatitis B virus carriage, and lepromatous leprosy, while increasing susceptibility to HIV-1 infection and tuberculoid leprosy. ${ }^{2122}$ Thus these polymorphisms known to be associated with osteoporosis and now in this study with Crohn's disease may have been positively selected by conferring resistance to infectious diseases.

This susceptibility effect for Crohn's disease that we have detected is relatively weak, which may be a function of phenotypic and genetic heterogeneity. However, susceptibility to inflammatory bowel disease is probably mediated by the effect of many polymorphic genes, each having only a relatively modest effect on its own, interacting together with environmental factors. It will be important to attempt to replicate these preliminary data in other datasets and in different ethnic groups, and to fully determine the functional implications of this polymorphism for immune regulation.

We thank Dr Nigel Morrison for unpublished sequence data. JDS is a Wellcome Trust clinical research training fellow.

1 Satsangi J, Parkes M, Louis E, et al. Two stage genome-wide search in inflammatory bowel disease provides evidence for susceptibility loci on chromosomes 3, 7 and 12. Nat Genet 1996;14:199-202.

2 Curran ME, Lau KF, Hampe J, et al. Genetic analysis of inflammatory bowel disease in a large European cohort supports linkage to chromosomes 12 and 16. Gastroenterology 1998;115:1066-71.

3 Duerr RH, Barmada MM, Zhang L, et al. Linkage and association between inflammatory bowel disease and a locus on chromosome 12. Am F Hum Genet 1998;63:95100
4 Baker AR, McDonnel DP, Hughes M, et al. Cloning and expression of full-length cDNA encoding human vitamin expression of full-length cDNA encoding human vit

D receptor. Proc Nat Acad Sci USA 1988;85:3294-8.
5 Whitfield GK, Hsieh J, Jurutka PW, et al. Genomic actions of 1,25-dihydroxyvitamin D3. F Nutr 1995;125:1690S-4S.

6 Provvedini DM, Tsoukas CD, Deftos LJ, et al. 1,25dihydroxyvitamin D3 receptors in human leukocytes. Science 1983;221:1181-3.

7 Koeffler HP, Reichel H, Bishop JE, et al. Gamma-interferon stimulates production of 1,25-dihydroxyvitamin D3 by normal human macrophages. Biochem Biophys Res Commun 1985;127:596-603.

8 Rook GA, Steele J, Fraher L, et al. Vitamin D3, gamma interferon, and control of proliferation of Mycobacterium tuberculosis by human monocytes. Immunology 1986;57: 159-63.

9 Lemire JM, Archer DC, Beck L, et al. Immunosuppressive actions of 1,25 dihydroxyvitamin D3: preferential inhibition of Th1 functions. $\mathcal{F}$ Nutr 1995;125:1704-8S.

10 D'Ambrosio D, Cipitelli M, Cocciolo MG, et al. Inhibition of IL-12 production by 1,25 dihydroxyvitamin D3. Involvement of NF-kappa B downregulation in transcriptional repression of the p40 gene. 7 Clin Invest 1998;101: tional rep

11 Morrison NA, Qi JC, Tokita A, et al. Prediction of bone density from vitamin D receptor alleles. Nature 1994;367: 284-7.

12 Gross C, Eccleshall TR, Malloy PJ, et al. The presence of a polymorphism at the translation initiation site of the vitamin $\mathrm{D}$ receptor gene is associated with low bone mineral density in post-menopausal Mexican-American women. $\mathcal{F}$ Bone Miner Res 1996;11:1850-5.

13 Wood RJ, Fleet JC. The genetics of osteoporosis: vitamin D receptor polymorphisms. Annu Rev Nutr 1998;18:233-58.

14 Ingles SA, Ross RK, Yu MC, et al. Association of prostate cancer risk with genetic polymorphisms in vitamin D receptor and androgen receptor. $\mathcal{F}$ Natl Cancer Inst 1997;89:166-70.

15 Hill AV. The immunogenetics of human infectious diseases. Annu Rev Immunol 1998;16:593-617.

16 Miller S, Dykes D, Polesky H. A simple salting out procedure for extracting DNA from human nucleated cells. Nucleic Acids Res 1988;16:1215.

17 Lo YD, Patel P, Newton CR, et al. Direct haplotype determination by double ARMS: specificity, sensitivity and genetic applications. Nucleic Acids Res 1991;19:3561-7.

18 Mocharla H, Butch AW, Papas AA, et al. Quantification of vitamin D receptor mRNA by competitive polymerase vitamin $\mathrm{D}$ receptor mRNA by competitive polymerase
chain reaction in PBMC: lack of correspondence with common allelic variants. f Bone Miner Res 1997;12:72633.

19 Verbeek W, Gombart AF, Shiohara M, et al. Vitamin D receptor: no evidence for allele-specific $\mathrm{mRNA}$ stability in cells which are heterozygous for the Taq1 restriction enzyme polymorphism. Biochem Biophys Res Commun 1997;238:77-80.

20 Pallone F, Monteleone G. Interleukin 12 and Th1 responses in inflammatory bowel disease. Gut 1998;43:735-6.

21 Bellamy R, Ruwende C, Corrah T, et al. Tuberculosis and chronic hepatitis $B$ virus infection in Africans and variation in the vitamin D receptor gene. F Infect Dis 1999;179:7214 .

22 Roy S, Frodsham A, Saha B, et al. Association of vitamin D receptor genotype with leprosy type. F Infect Dis 1999;179: $187-91$ 